\section{MITRE Y LA CONSTRUCCIÓN NACIO- NAL: DEL HOMBRE DE PRINCIPIOS AL POLÍTICO PRAGMÁTICO}

MITRE AND THE NATIONAL BUILDING:

FROM THE MAN OF PRINCIPLES TO

THE PRAGMATIC POLITICIAN

HILDA SABATO •

Instituto de Historia Argentina y Americana «Dr. Emilio Ravignani», Facultad de Filosofía y Letras, Universidad de Buenos Aires (Argentina).

Mi primera reacción frente a la obra que hoy presentamos es de admiración: si narrar la vida de cualquier ser humano representa un desafío para quienquiera que se proponga hacerlo, animarse con la de Bartolomé Mitre es enfrentar un reto colosal. Y este es el paso que ha dado Eduardo con el resultado que tenemos entre manos: una obra histórica sustantiva, imprescindible.

Quiero destacar, en segundo lugar, que este libro es parte de la colección que ya se ha convertido en clásica entre nosotros, la de «Biografías argentinas» de editorial

\section{Registro bibliográfico}

SABATO, HILDA «Mitre y la construcción nacional: del hombre de principios al político pragmático», en: ESTUDIOS SOCIALES, revista universitaria semestral, año XXIX, $n^{\circ} 56$, Santa Fe, Argentina, Universidad Nacional del Litoral, enero-junio, 2019, pp. 241-246.
Edhasa, dirigida por Gustavo Paz y Juan Suriano. En el marco de la revalorización de la biografía como género, esta excelente iniciativa ha dado lugar a diferentes ejercicios de escritura biográfica, pues no hay un formato preestablecido y cada autor/historiador ha realizado su propia experiencia en ese sentido. Contamos así con un conjunto ya significativo de historias de figuras notables (casi todos hombres...) de nuestro pasado al que ahora se suma esta contribución fundamental.

Volvamos, pues, a ella. Frente a la inmensa tarea entre manos ¿qué se propuso

\section{Descriptores · Describers}

biografía / construcción nacional / Eduardo Míguez / Bartolomé Mitre biography / national building / Eduardo Míguez / Bartolomé Mitre

Recibido: 28/09/2018 Aceptado: 03/12/2018 
Eduardo? En sus palabras: «esta obra se propone entender al personaje en relación con el proyecto de nación liberal», «relatar y analizar no sólo la vida de un importante actor de la historia argentina en sí, sino su papel en el proceso en que se insertó». Para ello, pone el foco en la dimensión política de esa historia, dejando de lado otras facetas de su compleja trayectoria. Y nos aclara porqué: «La vocación política fue el motor de la vida de Mitre; $y$-siguela mayor parte de su labor intelectual, una dimensión más de ella...». Retomaré este punto más adelante.

Con ese propósito general, ¿`cómo arma su relato? Predomina aquí la opción por el seguimiento cronológico de la trayectoria del personaje, con una sola excepción en el capítulo 2 dedicado a «el pensamiento de Mitre y su evolución en el tiempo", donde arroja una mirada sobre los principales núcleos de ideas que obrarían en buena medida como principios orientadores de su quehacer como hombre público, así como sobre el desarrollo de sus prácticas intelectuales, en particular en el campo de la historia. Distribuidos en tres partes, el resto de los capítulos sigue un ordenamiento cronológico, aunque está claro que no todos los tiempos de esta larga vida particular son equiparables: dedica una mitad del total del libro a los 16 años que van de 1852 a I868, seguramente porque fueron los de su mayor incidencia en la vida pública argentina.
Luego de una introducción relativamente breve, un primer capítulo aborda el origen familiar y los primeros treinta años de la vida de Mitre. Allí, su perfil va cobrando singularidad a partir de las opciones que fue tomando en medio de un contexto que el autor describe muy bien. Luego de la interrupción del relato cronológico del segundo capítulo sigue un tercero, que cierra la primera parte llamada «Surgimiento de un líder». Este está dedicado a los muy densos años entre I852 y I860, cuando comienza la actividad más directamente política de Mitre en la ciudad con la que elegiría identificarse, Buenos Aires. A diferencia del primer capítulo donde el personaje aparecía en toda su indeterminación, aquí lo vemos prácticamente formado: Mitre ya es MITRE, la figura histórica que no habría de cambiar demasiado. Al mismo tiempo el foco del relato se va corriendo, en la medida en que Eduardo concentra mucho de su análisis en el conjunto del panorama político del momento, una tendencia que se acentúa en la segunda parte, «La construcción de la nacionalidad».

Con sus tres capítulos dedicados al primer quinquenio de la década del 6o, esta parte constituye el núcleo del libro, dondesigue con detalle la historia de la Argentina durante esos años en que Mitre ocupó el centro de la escena política, como gobernador de Buenos Aires, como gobernador a cargo del PE y, final- 
mente, como presidente de la república Argentina unificada. Se presenta aquí, como bien dice el texto de tapa, un excelente fresco histórico de la Argentina del momento, donde se insertan los proyectos y la labor institucional y política de nuestro personaje. Son, también, los años en que parece cumplirse el destino por él sońado de forjador de la nación, desde la ciudad elegida, Buenos Aires. Los altibajos y contratiempos propios de una realidad que no responde a sus ideales no alcanzan para detenerlo $\mathrm{u}$ obstruirle su paso al éxito, aunque deba muchas veces resignar principios en pos de alcanzar y mantener el poder.

Lo que sigue, la tercera parte, «El poder o la gloria", marca un cambio de rumbo en ese camino, pero Mitre encara los contratiempos de la nueva etapa reorientando su accionar sin arriar sus principales banderas y, sobre todo, sin dudar de sus mandatos como hombre público. El tiempo alargado del primer capítulo, dedicado a los apenas tres años del final de su presidencia, es quizá el más complicado para él, pues se interrumpe su glorioso derrotero anterior. Marcado por la guerra -externa e interna- habría de torcer el rumbo de su ascenso y desembocar en una sucesión no deseada, que lo marginaría de los primeros planos. A partir de allí, el texto sigue el panorama nacional volviendo el foco a un Mitre que busca una y otra vez recuperar protagonismo, fallando siempre, hasta que encuentra su lugar en el espacio simbólico al que de todas maneras siempre había aspirado - tal vez más tarde que lo que lo obligaron las circunstancias-: el del héroe de la nacionalidad argentina.

En este recorrido vital, Eduardo toma distancia tanto de las versiones más apologéticas como de las más críticas de su personaje, para construir un Mitre históricamente situado, en el cruce entre pensamiento y acción, entre su voluntad personal de cambio y un pragmatismo que lo lleva a adaptarse a los imperativos de lo ya dado. Eduardo también se abre paso con inteligencia entre las huellas construidas que dejó este forjador cuidadoso de la imagen de sí mismo dispuesto a ocupar un lugar central en el panteón de la patria. La riqueza y complejidad de este libro torna imposible hacer justicia a todos los temas que recorre, por lo que voy a centrarme a continuación en lo que considero el motivo articulador de todo el texto y, también, de la vida del propio Mitre. De él nos dice Míguez en la introducción: «dedicó la parte más notable de su vida a intentar poner en práctica un enorme proyecto: la construcción de una nación sobre las bases del republicanismo liberal». Desde temprano, todos sus esfuerzos habrían estado puestos al servicio de ese objetivo, que se alcanzó con éxito. Pero si bien Mitre fue protagonista de ese proceso, los resultados del mismo estuvieron lejos del modelo inicial, no solo porque 
otros ideales y otras propuestas de nación se cruzaron en el camino sino porque los avatares de la vida política práctica llevaron el propio Don Bartolo a resignar muchas veces sus principios.

Eduardo es muy convincente en su análisis de las bases ideológicas -por llamarlas de alguna manera- del pensamiento de su biografiado y traza con detalle los orígenes de su inclinación republicana así como de su desarrollo posterior. La atención que presta a la relación con las figuras de Mazzini y Garibaldi le permite completar el cuadro de las más tradicionales referencias a las influencias de franceses y norteamericanos. Como señala el autor, en los años de la formación de Mitre el republicanismo liberal (en sus muchas variantes) era un piso común compartido por muchos de su generación en Hispanoamérica y allí había abrevado nuestro hombre en su adopción de ciertos principios políticos a los que se aferraría durante buena parte de su vida y que presumiblemente guiarían su accionar.

El problema, nos dice Miguez, es que la vida política argentina de todo el período no respondía para nada a los ideales que suponía ese republicanismo que inspiraba a Mitre. La tensión entre principios y realidad se convierte así en un leit motiv de esta biografía, donde una y otra vez su protagonista sostiene en su pensamiento y en su retórica sus principios guía, pero en la práctica política se entrega (casi re- signadamente) a un pragmatismo que impide cualquier intervención efectiva para cambiar los parámetros dominantes. Mitre termina así adoptando y reforzando los rasgos de un régimen político que contradice sus principios y que se mantiene igual a si mismo desde Caseros hasta I9I6. Debo confesar que este punto no me convence y no porque tenga otro diagnóstico acerca de la vida política de este período (que lo tengo) sino porque entre la aplicación a rajatabla de ciertos principios ideológicos y el puro pragmatismo se abre la interrogación acerca de las intervenciones efectivas que Mitre ensayó como actor, como animador de la vida política - un rol que jugó toda su vida. En el plano del régimen político, sus propuestas y sus intervenciones normativas e institucionales, fundadas en buena medida en sus principios liberal republicanos:̨no fueron parte importante de las formas que adoptó ese régimen en las primeras décadas de la república? Y en ese sentido, ¿no se pueden trazar algunas relaciones entre unas y otras?

Por otra parte, en el plano de la política práctica, el libro se detiene sobre todo en la "gran política», por decirlo así: esto es, de los manejos institucionales, de los intercambios entre dirigencias, de las idas y venidas de las candidaturas. Pero no se pregunta por la dinámica política más general, la que movilizaba a gentes muy diversas encuadradas en formas de 
intervención que resultaban tanto de los marcos institucionales -en tanto electores, milicias, y públicos de diversa layacomo de la acción política misma en que las dirigencias estimulaban esa participación que no necesariamente respondía al perfil de la clientela incondicional. En ese sentido, Mitre tuvo un papel no menor, sobre todo en el caso de Buenos Aires. Eduardo señala bien que Mitre quería encarnar/encabezar a una aristocracia con base en esa provinciaque debía conducir la nación. Esa figura no era, sin embargo, contradictoria con la del caudillo urbano, al que seguían y admiraban sectores amplios del público porteño, a los que el cultivaba cuidadosamente a través de sus relaciones personales, sus escritos en la prensa y sus discursos en diferentes ámbitos, su participación en mitines y festejos, y aún su involucramiento en revoluciones. Ese público era fundamental a la hora de legitimar su figura política de patricio republicano (también para sí mismo), en la medida en que la figura de la «opinión» no solo era clave en su proyecto, sino que también lo era en la concepción predominante en la época acerca de la legitimidad del poder político en su relación con el «pueblo» abstracto.

Esa dimensión no era, pues, apenas una anécdota de color, sino uno de los pilares sobre los que funcionaba el régimen del momento. Y Mitre jugaba fuerte en esa cancha, por lo queproyectó esa figura ha- cia el interior de la provincia y lo intentó también, con desigual fortuna, más allá de sus fronteras. Esta faceta -me parece- podría ofrecernos pistas para complejizar esa dicotomía tan tajante que se plantea entre principios ideales y prácticas pragmáticas de dirección opuesta, y para entender mejor su personalidad política. También para interrogar cuánto incidieron esas prácticas, así como algunas de sus intervenciones en el plano institucional, en los contornos del régimen político.

Son estos algunos de los temas que este libro en toda su riqueza abre a la reflexión. Hay mucho más, pero se acaba el tiempo. No quisiera terminar sin hacer una referencia a dos tramos de esta obra sustantiva que me resultaron particularmente iluminadores. Me refiero a los que se internan en las relaciones y los paralelos entre Mitre y dos otras figuras centrales del período: Urquiza y Sarmiento. En un texto con muchos aciertos, estos contrapuntos se destacan por poner el foco en los actores mismos, más que en el contexto. En estas páginas, es posible «ver»a estos hombres en movimiento, con sus intereses, empatías, pasiones y ambiciones. Frente a las caricaturas planas frecuentes en nuestra literatura histórica se proponen aquí imágenes ricas en matices para hablar de cada uno así como también de las cambiantes relaciones privadas entre ellos, que tendrían, por su parte, decisivas consecuencias públicas. Hombres al fin, 
más allá de las circunstancias, forjaron y po asignado, quiero agradecer a Eduardo rompieron lazos impulsados por amores y por esta obra, que expande nuestro coodios al calor de sus razones pero también nocimiento y alimenta el debate sobre de sus emociones.

un hombre y un período fundamental de

Llegados a este punto y al final del tiem- nuestra «nacionalidad». 